\title{
Literatura infantil y educación primaria: análisis del valor formativo de los libros más leídos en España
}

\author{
Eduardo Encabo-Fernández \\ Isabel Jerez-Martínez ${ }^{* *}$
}

\section{Resumen}

El propósito de esta aportación es mostrar cuál es la relación que se establece entre los libros más leídos en Literatura Infantil en Espańa, concretamente en el nivel de Educación Primaria. Tratamos de averiguar si el valor formativo de los mismos es el adecuado o si los textos únicamente responden a un criterio comercial. Debatiremos en el interior de esta aportación cuestiones relevantes como la posibilidad del establecimiento de un canon formativo y las dificultades que ello conlleva, el desarrollo de la lectura y la Literatura Infantil en el currículo oficial o el mismo análisis pormenorizado de todas aquellos textos que son los más demandados, comprados y leídos por la población infantil española.

Palabras clave: Literatura Infantil. Formación de maestros. Promoción de la lectura.

* Profesor titular del Departamento de Didáctica de la Lengua y la Literatura de Universidad de Murcia, España.

** Profesora ayudante doctor del Departamento de Filología Hispánica y Clásica (área de Didáctica de la Lengua y la Literatura) de Universidad de Castilla-La Mancha, España. 


\section{Introducción}

Esta aportación pretende reflexionar sobre la importancia de la Literatura Infantil en Educación Primaria, concretamente intenta averiguar qué está ocurriendo con los textos más leídos y si estos están conformando un tipo de pensamiento concreto si nos referimos a la formación de las nuevas generaciones. Es trascendente describir la realidad lectora ya que la teoría y las condiciones de aprendizaje plantean situaciones idílicas para la educación pero no se detiene a conocer qué es lo que realmente lee el alumnado y sobre todo, si dichos textos poseen la calidad y contenidos idóneos para el mismo.

Tenemos que ser conscientes de que la formación lectora es una preocupación del área de conocimiento de Didáctica de la Lengua y la Literatura. Por ello, desde nuestro punto de vista su concepción y tratamiento va más allá de la escolaridad obligatoria y entronca con el denominado aprendizaje permanente (CONSEJO DE EUROPA, 2006). Desde esta perspectiva, consideramos altamente relevante el hecho referido a que las personas adquieran y consoliden un criterio para poder seleccionar y leer textos de calidad y esta labor comienza en los primeros niveles de enseñanza.

Concebida la lectura como algo dinámico, en la línea apuntada por Cerrillo (2007), el papel del mediador de la lectora es vital si queremos que la labor sea realmente significativa. Esto implica que docentes, padres o bibliotecarios se conviertan en lectores críticos y ayuden a entender el texto como un objeto de reflexión, haciendo que el alumnado pueda ser selectivo y de igual modo, pueda opinar sobre las lecturas que realiza.

Uno de los debates trascendentes que afectan a este texto tiene que ver con la naturaleza de los textos infantiles considerados como tales, así pues tendremos que distinguir el criterio principal de consideración para ver si lo que lee el alumnado es legítimo como Literatura Infantil o si bien es la opinión del adulto mediador la que tiene que prevalecer.

\section{¿Literatura Infantil o Literatura de los niños?}

Se introduce esta cuestión ya que es una de las preguntas clave de la trayectoria de la disciplina. A veces se limita el ámbito de esta Literatura al criterio del adulto mediador o al criterio social que viene establecido por los medios o mercado, pero, ¿qué ocurre con la opinión de los niños? ¿¿ería más 
correcto hablar de una Literatura de los niños ya que son éstos los que hacen suyos los textos? Parece que esta última situación es la más coherente pero restaría capacidad de maniobra para los adultos educadores. Por esa razón, en ocasiones existe cierta incoherencia entre lo que se lleva al aula por parte del profesorado mediador y lo que realmente demanda el nińo. Conocer los intereses del niño o simplemente que éste se aproxime con libertad al texto es una práctica anunciada y reflexionada de manera teórica pero que en la práctica no termina de ser algo extendido.

La situación se agudiza cuando desde determinados sectores se menciona la Literatura Infantil como Literatura sin establecer límites o características concretas por parte de cada una. Por una parte, este razonamiento tiene su sentido ya que la Literatura para niños no deja de ser literatura, compartiendo rasgos similares con la misma pero, por otra parte, el mercado generado sobre esta materia no admite su negación. Por tanto, la vigente discusión no permite una consolidación total de la materia generando en ocasiones indefiniciones o prácticas contradictorias que finalmente redundan en algo negativo para los niños.

En la línea de reflexión apuntada observamos cómo, en muchas ocasiones, se versionan clásicos de la Literatura indicando que los mismos al sufrir la adaptación se transforman en Literatura Infantil. Desde nuestro punto de vista esta situación sería cuestionable ya que el texto inicial es modificado y con la transformación no aseguramos el éxito o aceptación por parte de los niños. Por consiguiente, ¿se pueden establecer límites en lo concerniente a la Literatura Infantil? Desde nuestra óptica los límites de la Literatura Infantil y Juvenil no se pueden constreñir a textos pedagógicos sino que deben abarcar un amplio espectro de obras que redundan en el mundo imaginativo, de los valores, y sobre todo, de la oposición entre el mundo adulto y el mundo infantil con todas las connotaciones que ello conlleva. Es decir, en principio no tendría que haber un límite, únicamente aquel que va marcando el niño al desechar obras que para él no tienen valor y que por tanto no les confiere el valor de infantiles. Esto no quiere decir que con posterioridad en época adulta no pueda retomar dicho texto.

Sí que nos gustaría indicar la reversibilidad de los textos considerados como Literatura Infantil, la concepción inicial del texto al no estar planteado para niños (ejemplos clásicos, Pinocho, Peter Pan, Alicia en el país de las Maravillas, etc.) motiva que el adulto pueda acceder al mismo aunque haya tenido trato 
con él en etapas más tempranas de su vida, aunque también es cierto que es la propia sociedad la que censura a la persona adulta cuando maneja un texto que ha sido considerado como infantil. Ésta es la gran contradicción de esta literatura, teniendo características de la Literatura denominada con mayúsculas, en muchas ocasiones es repudiada por los adultos al considerar estos que su duración es limitada y que sólo personas de una determinada edad pueden ser usuarios de las mismas. Pese a todo la ingente cantidad de textos de Literatura Infantil que se publican al año debe suponer un aumento de la consideración social de la misma al convertirse en un campo trascendente de lectura y estudio.

\section{La proliferación de la Literatura Infantil en los últimos tiempos}

Referirnos a Literatura Infantil y Juvenil supone adentrarse en un ámbito que se encuentra en continua expansión. Nos trasciende una atmósfera capitalista y el hecho de que se aprecie una posibilidad mercantil relacionada con la Literatura Infantil, provoca que hay una expansión que se traduce en forma de numerosas publicaciones por parte de mundo editorial y de compras por parte de las personas usuarias. La laxitud de su definición y la variedad de textos que se van incorporando a la misma hace que acotar este tipo de Literatura y aproximarse a ella se convierta en todo un reto. No podemos obviar su relativa juventud ya que poco más de dos siglos contemplan el reconocimiento de la Literatura Infantil y Juvenil; la historiografía se convierte pues en un obstáculo para una adecuada consideración social de la misma. Pese a que existen aportaciones que tratan de reflexionar sobre el estado de la cuestión (COLOMER, 1999; CERRILLO; GARCÍA-PADRINO, 2000; CERRILLO, 2007) sigue siendo complicado contemplar una historia sólida de esta modalidad literaria. Siempre el conflicto emerge cuando nos planteamos si podemos segregarla de la Literatura general y convertirla en algo específico. González Gil (1979, p. 278) menciona:

Literatura General y Literatura Infantil tienen unas características comunes; pero, a veces, no es suficiente añadir unas notas diferenciadoras para clarificar nuestra cuestión. La realidad es compleja y observamos hechos como el siguiente: se encuentran nińos y adultos que se identifican y satisfacen con obras literarias idénticas, o 
una obra literaria gusta a un adulto y a varios nińos... ¡Difícil delimitación la que tiene que contar con el gusto y la libertad del arte!

También las cuestiones de definición afectan al tipo de textos que componen esta literatura. Por ejemplo, desde nuestra óptica, en ocasiones se considera que los libros o recursos pedagógicos forman parte de esta literatura cuando en realidad son apoyos para la educación pero no poseen un argumento definido o una capacidad narrativa consistente que permita considerarlos Literatura Infantil. Así pues, no podemos citar alegremente el término infantil unido a la literatura. En ocasiones se realiza socialmente esta alusión de manera despectiva generando el desprestigio y perder la importancia que en realidad posee en el sistema social y educativo.

Actualmente, en el ámbito social existe un lugar para la Literatura Infantil. Ediciones SM (GRUPO SM, 2011) nos aporta datos relativos al consumo en el sector que creció en volumen $(11,9 \%)$ y en valor $(11,4 \%)$ casi el triple que el total del sector del libro. La facturación en literatura infantil y juvenil ascendió a 327 millones de euros, creciendo en los últimos cinco años aproximadamente un $20 \%$. La Literatura Infantil y Juvenil representa actualmente un $10 \%$ del total del mercado del libro. Sin embargo, 2010 se mostró como el año en el que la literatura infantil y juvenil no pudo escapar de la crisis económica. Así, vio mermados los números positivos mostrados en la última década. Se puede señalar que la Literatura Infantil y Juvenil ha atravesado un momento de gran expansión, incluso ha mostrado una fortaleza superior al resto de sectores del libro. Muchos factores intervienen en la configuración de estos datos favorables, pero uno de los principales tiene que ver con la aparición del fenómeno vampiros, el cual ha creado una categoría literaria propia y específica que aborda temas fantásticos y trata de hacer un guiño a la novela romántica (muy apreciada por el público femenino). Dicho fenómeno correspondería a la Literatura Juvenil, pero en el ámbito infantil también apreciamos ejemplos concretos como pueda ser la colección de Gerónimo Stilton.

Autores como Mendoza (2005) nos han revelado su impresión relativa a que la Literatura Infantil no debe ser enseñada sino disfrutada, alejándose en gran medida de la utilización de este tipo de Literatura dentro de las aulas. Por el contrario en diferentes publicaciones también se ha defendido la importancia de la Literatura Infantil, su carácter transversal y por ende su inclusión como 
recurso fundamental en los diseños educativos. Este planteamiento no tiene una solución sencilla ya que ambas posturas son respetables. Como suele suceder la propuesta de la búsqueda de la utilización compensada suele ser la mejor solución sugerida.

\section{El canon formativo: el debate sobre su indefinición}

Uno de los grandes temas para debatir en Literatura Infantil es la cuestión referida al canon formativo. Diversos investigadores del área (NÚÑEZ, 2001; DEL AMO, 2003; BORDA, 2003; REDONDO; GÓMEZ LÓPEZ, 2003; TEJERINA, 2004; GARCÍA-PADRINO, 2004; DELGADO, 2009; COSTA, 2011) han hecho camino en la búsqueda de un consenso relativo a la cuestión, pero todo se topan con una indefinición y es que el hecho de que el reconocimiento de la Literatura Infantil sea cuestionable arrastra cualquier reflexión que en torno a la misma se haga, esto es, si la disciplina no tiene una consolidación y reconocimiento social determinado, no es posible establecer un canon formativo. Por ejemplo, nadie podría discutir que ciertos clásicos de la Literatura Infantil deberían ser conocidos y leídos por las personas. Así, Alicia en el país de las maravillas, Peter Pan o El Mago de Oz, cumplirían los requisitos para formar parte de ese canon. Ahora bien, ¿qué ocurre si un crítico estima que estos textos no son obras infantiles sino que son obras de la Literatura que por mor de sus adaptaciones han sido consideradas infantiles? Ocurre que queda desmontada dicha inclusión y el canon vuelve a estar indefinido. Por esta razón, la labor en Literatura Infantil es harto complicada ya que al no tener una idea clara y una consolidación social, las dudas siempre asaltan al estudioso o investigador.

Otro ejemplo de inclusión en el posible canon podría ser Roald Dahl, el autor galés ampliamente conocido y estudiado podría ser objeto de consenso ya que su obra sí parece específicamente destinada para nińos, pero si aplicásemos un criterio educativo para considerar un texto idóneo para ser incluido en el canon, y ese criterio optase por un determinado principio de bondad y comportamiento ejemplar por parte de los personajes que participan en la historia, es posible que la obra de Roald Dahl tuviese que ser descartada.

Más reciente es la situación del texto de impacto mundial que supone Gerónimo Stilton, en este caso la expansión y conocimiento del texto hace que sea una obra relevante debido a que gran cantidad de niños conoce la misma. Esto 
podría suponer su inclusión en el canon pero, si aplicamos un criterio referido a la calidad literaria, posiblemente tuviésemos que descartar esta situación. Este ejemplo nos muestra la complejidad de proponer un canon formativo, ya que la heterogeneidad de la Literatura infantil y las múltiples dimensiones que afectan a la misma constituyen un problema en esta definición. Además, a esto tenemos que añadir la tradición occidental de la que somos objeto y que en la mayoría de las ocasiones olvida la existencia de producciones procedentes de oriente. Teóricos de la Literatura como Harold Bloom (2005) o Pozuelo y Aradra (2000) de alguna manera han orientado la definición del canon hacia lo occidental olvidando la riqueza de aportaciones que desde otras latitudes se realizan.

En todo caso pese a no tener un canon perfectamente definido sí que podemos indicar que cada sociedad mediante los textos que selecciona para incorporar en la institución educativa y sobre todo con aquellos con los que se práctica una importante política de marketing, crea micro-cánones (POZUELO, 1996), los mismos condicionan de forma ideológica la formación de las personas y como veremos más adelante, en muchas ocasiones su valor formativo es discutible ya que es posible que no dejen que las personas puedan desarrollar una perspectiva crítica con respecto de argumentos y temáticas sino que simplemente se dejen arrastrar por el encorsetamiento del texto y de sus personajes.

\section{La Literatura infantil en el currículo oficial español. Apreciaciones}

El BOE núm. 173 de 20 julio de 2007 (ESPAÑA, 2007) establece el currículo y regula la ordenación de la Educación Primaria en España. Hemos incluido el mismo ya que ofrece cobertura a todo el territorio nacional. Somos conscientes de que cada comunidad autónoma recoge sus enseńanzas mínimas en decretos currículos propios, pero para nosotros son más interesantes las cuestiones comunes que puedan derivarse de las directrices de esta orden. Así pues, seleccionamos de la misma aquellos aspectos que atañen específicamente a la lengua y a la literatura para que el alumnado tenga una referencia del tratamiento de la lectura y más concretamente de la Literatura Infantil en el citado currículum

Analizando el currículum (ESPAÑA, 2007) en sus distintas etapas, comprobamos que, legislativamente, el mismo no ofrece a los docentes y educadores pautas explícitas a la literatura infantil, confiriendo cierta libertad 
para escoger los textos que se manejen en las aulas. Por una parte esta situación es positiva ya que el profesorado tiene libertad para seleccionar las obras que considere oportunas para su realidad y así puede adaptar los mismas a las necesidades de los estudiantes pero al mismo tiempo, esta situación puede convertirse en algo peligroso porque los docentes pueden optar por la comodidad y no buscar textos de literatura infantil para trabajar con el alumnado. Es frecuente que los libros de textos espańoles contengan fragmentos narrativos (que no pertenecen a la Literatura infantil) que guían la práctica diaria del profesorado. Así, indicaciones como por ejemplo: Valoración de la autonomía lectora, interés por la elección de temas y textos, por la comunicación de las preferencias personales, y apreciación del texto literario como recurso de disfrute personal, son las que ofrece el currículo oficial a los docentes. Una de las pocas alusiones explícitas que se realiza con respecto de la Literatura Infantil es: Lectura personal, silenciosa y en voz alta, de obras adecuadas a la edad e intereses. Lectura guiada de textos narrativos de tradición oral, literatura infantil, adaptaciones de obras clásicas y literatura actual en diferentes soportes. Lectura comentada de poemas, relatos y obras teatrales teniendo en cuenta las convenciones literarias (géneros, figuras.), y la presencia de ciertos temas y motivos recurrentes. Pero, como observamos, se encuentra camuflada entre otro tipo de recomendaciones o intereses.

Al suceder esto con lo prescriptivo, es lógico que la sociedad tenga predominancia con lo que ocurre en las aulas y por ello podamos encontrar textos que se asimilan a la literatura infantil que posiblemente no contribuyan a la formación de personas pero que son utilizados por determinados padres o educadores para dárselos a los niños. De este modo no existe una utilización ideal de la literatura infantil en educación ya que acontece la circunstancia referida a que en ocasiones el mercado tiene predominancia sobre el valor formativo de los textos cuando en Educación Primaria es fundamental sentar las bases del comportamiento de los nińos para que se puedan ir insertando de un modo óptimo en las estructuras sociales.

\section{La importancia de la Literatura Infantil en las aulas de Educación Primaria}

No es algo caprichoso el incluir esta sección en nuestra aportación. Ya nos indica Teresa Colomer (1999) que, la literatura infantil cumple las siguientes funciones: 
[...] iniciar el acceso a la representación de la realidad ofrecida a través de la literatura y compartida por una sociedad determinada; desarrollar el aprendizaje de las formas narrativas poéticas y dramáticas a través de las que se vehicula el discurso literario, y ofrecer una representación articulada del mundo que sirve como instrumento de socialización de las nuevas generaciones [...]. (COLOMER, 1999, p. 15).

Basándonos en las mismas, descubrimos que se unen de manera significativas a las aspiraciones curriculares que la institución educativa nos recomienda. Así, el acceso a la interpretación de la realidad es una de ellas, en este caso es totalmente significativo el instrumento mediante el cual los niños interpretan la realidad y sobre todo el escenario ficticio que se les ofrece para que, mediante el simbolismo, vayan aprehendiendo los valores y conocimientos que la realidad les transmite. Por ello, es tan importante la selección del tipo de literatura a la que acceden. Un corte ideológico determinado motivará que, consciente o inconscientemente estas nuevas generaciones moldeen su pensamiento de una manera o de otra. Con esta reflexión no nos situamos en ningún lado de los modos de pensar sino que abogamos por la diversidad de materiales y la no circunscripción a una única forma de pensar.

La segunda función de las comentadas por Colomer (1999), supone familiarizarse con la estética y contenido del hecho literario, hecho fundamental para la formación de personas. Si es nuestro deseo que haya un desarrollo e inmersión cultural por parte de los niños tenemos que hacer que estén en contacto y sobre todo que hagan uso de la literatura, en este caso en su dimensión infantil. De ese modo, lograremos que su acceso a otras manifestaciones del ámbito cultural sea más sencillo. La última de las funciones mencionadas tiene que ver con la socialización que el niño va desarrollando mediante el uso de la literatura infantil. Es innegable que el hecho de identificarse con determinados personajes y acciones de los mismos va perfilando la personalidad y el comportamiento de los niños. También se moldean sus gustos y aficiones. Es necesario precisar que la capacidad de discernir es un aspecto fundamental, es evidente que una niña o un niño no se va a comportar en su realidad como lo puede hacer Pippi Langstrump, pero los comportamientos de la misma sí que le van a permitir conocer aspectos que están bien o mal considerados desde la normativa social. 
Así pues, las aulas de Educación Primaria constituyen un lugar esencial para la formación de las personas y para la utilización de la literatura infantil. Aunque el currículo oficial no desarrolle de un modo exhaustivo qué textos se pueden usar en este nivel educativo, el profesorado tiene que intentar estar al día de las novedades que se producen en la disciplina, y por supuesto, saber seleccionar los clásicos que en la misma existen, de tal manera que se haga una utilización adecuada del género se pueda cumplir con las tres funciones anteriormente descritas, las cuales son esenciales en el proceso de formación de la persona.

\section{La Literatura Infantil y Juvenil y los docentes}

En nuestra época se nos presenta una curiosa paradoja: sin duda nadie ha carecido de la presencia de textos infantiles en sus vidas pero, ¿̨realmente sirve para algo este tipo de Literatura en la sociedad caracterizada por lo tecnológico? En lo que concierne al profesorado, tanto en Educación Infantil como en Educación Primaria ha sido contemplada la materia Literatura Infantil en los planes de estudios confeccionados al efecto. El profesorado tiene en sus planes de estudio materias denominadas Literatura Infantil o bien, dicha denominación es sustituida por géneros contenidos en la materia o aspectos estrechamente relacionados con la misma. En cualquier caso, la asignatura debe estar contenida en dichos planes, pero desde nuestro punto de vista no son tan relevantes los títulos que se pueden tratar en la misma -prácticamente se desiste de la idea de tratar de llegar a un consenso en cuestiones de canon- sino que lo fundamental es infundir a ese alumnado, futuro profesorado, la comprensión de la idea de este tipo de Literatura, de manera que sea capaz de discernir la misma de otros textos y pueda ir configurando y adaptando textos para su posterior uso y aplicación en las aulas.

Recurriendo al ámbito escolar, diremos que en la etapa Infantil y en Educación Primaria tanto las cuestiones infantiles como juveniles, los cuentos, los textos fantásticos, las poesías, el cómic, todos llegan a conformar un ubérrimo corpus textual que da como resultado el reconocimiento de la Literatura Infantil y Juvenil. Todos ellos se convierten en un recurso didáctico de gran utilidad para el profesorado, ya que en él se encuentran reflejados buena parte de los contenidos curriculares que deben desarrollar a lo largo de los distintos ciclos. Dichas producciones artísticas (no olvidemos que una de las atribuciones que 
se hace a este tipo de literatura es la de su vinculación con el arte) son sinónimo de labor lingüística y literaria; en ellas se trabaja vocabulario, estructuras gramaticales, aspectos no verbales... Por otra parte, no se destierra la cara lúdica de la utilización de estos textos ya que la atención que generan, la emoción y el ritmo vivo y ágil, motivan que el entretenimiento sea una realidad con su uso.

Como hemos mencionado, es complicado establecer un canon de Literatura Infantil, e igualmente difícil pensar en los libros más significativos que corresponden a la misma. Por esa razón, hemos decidido que nuestra aportación escogiese aquellos textos que son más actuales y tienen un impacto mediático razonable.

\section{Los textos de Literatura Infantil y Juvenil usados en esta aportación}

Para el desarrollo de este texto hemos optado por aludir a los textos que más profusión tienen en la actualidad en el ámbito infantil. Por ello, hemos recurrido a estudio generado por la Federación de Gremios de Editores de España (2012). Por consiguiente, consultamos aquellos textos de Literatura Infantil más leídos y usados por los niños. En primer lugar, hallamos la colección Gerónimo Stilton, las aventuras de este simpático ratón arrasan en la etapa de Educación Primaria, siendo los más de cuarenta libros publicados los más utilizados por los más jóvenes. A continuación es el libro de Jeff Kinney, El diario de Greg, el segundo más leído. Este texto sencillo de leer, estructurado en forma de cómic también es motivo de gran uso por parte de la población infantil y juvenil. Otro de los textos más manejados en esta etapa es la colección de libros de Knister, Kika superbruja. Las aventuras de la pequeña bruja sin duda son muy atractivas para ser disfrutadas por los niños. También hay una gran producción de textos que tienen a este personaje como protagonista. Tras ella en cuarto lugar se encuentra el fenómeno mundial escrito por J. K. Rowling, Harry Potter, aludiendo en este caso a los siete textos relacionados con el joven mago. Poco se puede aportar ya de este personaje y sus libros ya que la producción en forma de estudios acerca del mismo es harto prolija. Como quinto libro más leído encontramos las aventuras de Tea Stilton, aprovechando el éxito de Gerónimo Stilton, se decidió que la igualdad de género tenía que ser un hecho y por eso se crearon historias similares a las del ratón pero encarnadas en la figura de su prima. Un clásico como Las crónicas de Narnia de C. S. Lewis ocupa el sexto 
lugar. Esto demuestra que los libros que ya poseen una trayectoria también son preferidos y leídos por la población infantil. Seguidamente, hallamos dos de los textos de la saga Crepúsculo que llegan a los últimos niveles de la etapa de Educación Primaria. Crepúsculo y Eclipse se sitúan entre los diez libros más leídos. Recordemos que, desde el año 2005 Stephanie Meyer irrumpió con fuerza en el ámbito juvenil convirtiéndose en un fenómeno mediático. El romance que entre Bella y Edward Cullen surge supone el estímulo fundamental para el público juvenil y por qué no decirlo entre edades comprendidas entre once y doce ańos. Otro éxito mundial como el texto de John Boyne, El niño con el pijama de rayas, está incluido entre los diez textos más leídos por la población infantil española. Completa el listado la obra de una autora española, Laura Gallego, en este caso, Memorias de Idhún, la trilogía donde tanto Jack como Victoria y Kirtash estarán predestinados a cambiar el destino de Idhún. La fantasía ubicada entre dos mundos es motivo de atracción para las personas lectoras. Favorece que este texto sea muy leído la adaptación a forma de cómic que recientemente se publicó.

Todas estas obras son las que más éxito tienen en la actualidad entre la población infantil española. Comprobamos que tan sólo una posee carácter nacional ya que el resto son internacionales. ¿Quiere esto decir que la globalización es un hecho constatado? Parece que sí ya que son fenómenos mediáticos traducidos en los distintos países aquellos que son más utilizados por los nińos. Además, estos libros llevan un poderoso sistema de merchandising asociado que hace que su conocimiento sea más sencillo. Está claro que estos libros son muy conocidos y leídos en el ámbito infantil, pero desde nuestra óptica de docentes tenemos que plantearnos si los valores transmitidos por estos textos realmente son óptimos para el proceso educativo, ya que, como sabemos, nuestra intención formativa incluye la diversión y la educación. Desde nuestro punto de vista no es suficiente con lo atractivo del texto y con la diversión que genera sino que es preciso que también lleve asociados ciertos valores que contribuyen a la formación de la persona.

\section{El valor formativo de los textos escogidos}

Analizando los textos escogidos podemos indicar que responden a la fisonomía de sociedad en la cual nos encontramos. El inicio del Siglo XXI hace que prime más lo efectista que lo conceptual, haciendo pues que los textos sean 
muy atractivos sin reparar en demasía en la calidad literaria de los mismos. El caso de Gerónimo y Tea Stilton es muy significativo, ambos textos en lo que respecta de sus paratextos, siguiendo las indicaciones de Gemma Lluch (1996) son un buen ejemplo de cómo hacer un texto atractivo. Las letras que varían de formato, las formas que éstas adquieren, los colores, etc., motivan que el libro sea un éxito entre la población infantil. Otra cuestión bien distinta es analizar su calidad literaria y los valores que transmite, ya que probablemente no sea el paradigma educativo deseado. Una situación similar acontece con la saga Crepúsculo, donde la calidad literaria es baja aunque el grado de impacto social es muy alto. Tal vez la cuestión referida a la comodidad y la rapidez con la que la persona lectora va transitando por las páginas hace que el éxito esté asegurado. Ahora bien, ¿nos interesa que el alumnado acceda a textos atractivos o que reflexione con ellos? En principio esta lista de diez libros más leídos por parte de los nińos y jóvenes muestra obras que contienen elementos atractivos y cuya lectura es rápida y sencilla.

Parece claro que el efecto comercial es determinante a la hora de leer textos de Literatura infantil y que podríamos considerar la situación referida a cierta manipulación de tipo social. Es evidente que si la sociedad es la que promociona estas lecturas es porque tiene un determinado interés en que sean leídas y su contenido es objeto de ser transmitido a los nińos. ¿Quiere esto decir que no se promociona la conciencia crítica hacia las lectura? Parece claro que la respuesta es positiva, aunque por otra parte, podemos pensar que no es necesario que en estas etapas del desarrollo las personas tengan que cuestionarse cómo y por qué se realizan las acciones o cuál es la causa por la que un personaje se comporta de una u otra manera. La etapa de Educación Primaria es una etapa relacionada con el juego y la diversión y por esta razón no podríamos criticar los textos que componen la relación de los más leídos en España. Ahora bien, si consideramos los contenidos curriculares y tenemos como filosofía docente el hecho de tratar de aprovechar formativamente los recursos que la sociedad, la familia y la escuela nos brindan, sí es evidente que tenemos que ser críticos con estos textos y demandar que los mismos sean completados y enriquecidos con textos clásicos o con lecturas de literatura infantil que sí posean la calidad necesaria para que el niño tenga el adecuado disfrute estético y sobre todo, para que repercuta en él el valor formativo de la lectura y de determinadas obras. Así pues, consideramos que estas obras que componen la relación de las más leídas en España en el ámbito de la Literatura Infantil, cumplen con la misión 
de ser atrayentes para el niño aunque sería discutible si su contenido formativo es el adecuado para esta etapa del desarrollo.

\section{Conclusiones}

Tras haber realizado esta aportación, comprobamos que los objetivos que nos habíamos planteado han sido alcanzados. Hemos sido capaces de analizar qué está ocurriendo con los libros más solicitados, comprados y leídos en España en el ámbito de la Literatura Infantil y estimar qué valor formativo poseen. Ahora extraemos una serie de conclusiones. La primera gran cuestión que surge es que de los diez libros aludidos, hay un gran conocimiento de los mismos debido a que poseen un gran marketing (caso de Crepúsculo, Harry Potter o Gerónimo Stilton). El caso de Gerónimo Stilton y Kika Superbruja es interesante ya que en las instituciones educativas españolas, concretamente en el nivel de Educación Primaria, son textos que poseen una gran difusión en el ámbito infantil y cuyos productos derivados de esos libros (merchandising $\mathrm{u}$ otras expresiones como series de televisión o películas) son ingentes. Los niños demandan estos textos pero, una pregunta que nos surge es: jestá preparado el profesorado para trabajar las posibilidades didácticas que la lectura y el conocimiento de los textos confieren al nińo? En ocasiones hemos comprobado cómo, maestros en formación o incluso en activo, desconocen estos personajes y prefieren centrarse en el manejo de los libros de texto. Sí es cierto que hemos mencionado que el valor formativo de estos textos puede ser puesto en duda, pero en el momento en el que los nińos conocen y manejan ampliamente estas lecturas se puede intentar el aprovechamiento didáctico de las mismas.

Por ejemplo, tanto Gerónimo Stilton como Kika superbruja poseen en sus colecciones relaciones con textos clásicos de la Literatura universal. Así Don Quijote de la Mancha aparece en uno de los volúmenes de Kika superbruja y, La isla del tesoro (Stevenson) y La Odisea (Homero) aparecen en textos de Gerónimo Stilton. Esta situación genera nuevas posibilidades didácticas para el profesorado que puede acercar al alumnado al concepto de la obra clásica y a ciertos personajes de la misma. Evidentemente no se trata de trabajar literariamente de un modo estricto sino que se incidirá en el disfrute estético y en la iniciación de los estudiantes en el ámbito literario. Será un buen modo de explotar las posibilidades didácticas de dichos textos los cuales son ampliamente conocidos. 
Otro aspecto importante que queremos reseñar en estas conclusiones es el que se relaciona con el problema del profesorado a la hora de no tener un concepto claro de la Literatura Infantil, no sabiendo establecer los límites de la misma, y queriendo deslindar aquellas edades que son inferiores a seis años de aquellas que las superan. De ahí que se produzcan problemas a la hora de conferir valoraciones. En ocasiones, acontece un problema lector evidente ya que conocer las obras sin haberlas leído puede ser algo paliativo pero el hecho de no leer provoca que la formación de profesorado no sea todo lo completa que debería y redunda en la construcción y situación social con la que nos encontramos en la actualidad. Un docente que no lee no puede convertirse en un buen modelo para los estudiantes ya que ellos buscan una referencia válida en el maestro. Si éste no genera expectativas y motivación por la lectura es complicado que los estudiantes desarrollen el gusto por la lectura. Además, si el profesorado no lee será casi imposible que pueda hacer buenas selecciones de textos y se limitará a escoger aquellas lecturas que sean más famosas o simplemente prescindirá de la lectura circunscribiéndose al libro de texto en el aula.

Así pues, podemos concluir esta aportación aludiendo a que los libros más leídos en Literatura Infantil tienen evidentemente una vertiente comercial y las cuestiones que se añaden a los mismos (versiones cinematográficas, merchandising, series de televisión) ayudan a que se conviertan en los más conocidos y seńa de identidad actual de esta literatura. En lo que concierne a formación de profesorado comprobamos cómo, éste debe tener un conocimiento más exhaustivo de la Literatura Infantil, debiendo ampliar sus criterios para poder seleccionar los mejores libros para sus estudiantes o, en el caso de que usen libros que tienen un gran impacto social considerar qué posibilidades didácticas pueden tener los mismos. Los docentes deben abogar por la búsqueda del valor formativo de la literatura infantil, para que éste complemente la vertiente lúdica que sin duda la misma posee. Tampoco podemos olvidarnos de la necesaria promoción lectora, ya que si no leen los textos no podrán realizar las oportunas valoraciones para poder seleccionar las obras. Concluimos esta aportación destacando la importancia de la Literatura infantil en la etapa de Educación Primaria y reivindicando su función como puente cultural entre la realidad del niño y la realidad que debe aprehender. Mediante las historias, los personajes y los comportamientos y acciones de estos últimos el niño va conociendo que es lo que sucede a su alrededor y sin ninguna duda va conformando su personalidad y modos de actuar. Así pues, no se debe permitir que la Literatura infantil 
sea considerada como un aspecto menor sino que, al estar incardinada en la Literatura, debe recibir el mismo trato que a esta última se confiere.

\section{REFERENCIAS}

BLOOM, Harold. El canon occidental: la escuela y los libros de todas las épocas. 5. ed. Barcelona: Anagrama, 2005.

BORDA, Isabel. Presencia de la literatura infantil y juvenil en el canon literario escolar. In: CANO VELA, A.; PÉREZ VALVERDE, C. (Coord.). Canon, Literatura infantil y juvenil y otras literaturas. Cuenca: Servicio de Publicaciones de la Universidad de Castilla - La Mancha, 2003. p. 377-386.

CERRILLO, Pedro. Literatura infantil y juvenil y educación literaria: hacia una nueva enseñanza de la literatura. Barcelona: Octaedro, 2007.

CERRILLO, PEDRO C.; GARCÍA-PADRINO, Jaime. (Coord.). Presente $y$ futuro de la Literatura infantil. Cuenca: Universidad de Castilla - La Mancha, 2000.

COLOMER, Teresa. Introducción a la literatura infantil y juvenil. Madrid: Síntesis Educación, 1999.

CONSEJO DE EUROPA. Recomendación del Parlamento Europeo y del Consejo no ${ }^{\circ}$ 394, de 18 de diciembre de 2006. Sobre las competencias clave para el aprendizaje permanente. Diario Oficial de la Unión Europea, Bruselas, 30 dic. 2006.

COSTA, Paulo. A experiência dos clássicos adaptados: caminhos ínvios na promoçáo da leitura de textos literários? Álabe: revista de investigación sobre lectura y escritura, Alméria, n. 4, dic. 2011. Disponible en: <http://nevada. ual.es:81/alabe/index.php/alabe/issue/view/4/showToc>. Acceso en: 5 mar. 2012.

DEL AMO, J. M. Historia de la literatura y canon infantil y juvenil. In: CANO VELA, A.; PÉREZ VALVERDE, C. (Coord.). Canon, Literatura infantil y juvenil y otras literaturas. Cuenca: Servicio de Publicaciones de la Universidad de Castilla - La Mancha, 2003. p. 367-376.

DELGADO, Fidel. Revisión del canon escolar: la figura del héroe. Hekademos: Revista educativa digital, Sevilla, año 2, v. 4, p. 57-72, 2009. 
ESPAÑA. Ministero de Educación y Ciencia. Orden ECI/2211/2007, de 12 de julio de 2007. Se establece el currículo y se regula la ordenación de la Educación primaria. Boletín Oficial del Estado, Madrid, 20 jul. 2007.

FEDERACIÓN DE GREMIOS DE EDITORES DE ESPAÑA. Hábitos de lectura y compra de libros en España 2011. Madrid: Dirección general del libro, archivos y bibliotecas/ Federación de Gremios de Editores de España, 2012.

GARCÍA-PADRINO, Jaime. El canon en la Literatura infantil o el debate interminable. Primeras noticias: revista de literatura, n. 205, p. 29-43, 2004.

GONZÁLEZ-GIL, Maria Dolores. Literatura Infantil: necesidad de una caracterización y de una crítica literaria. Cauce, Sevilla, n. 2, p. 275-300, 1979.

GRUPO SM. Anuario sobre el libro infantil y juvenil 2011. Madrid: SM, 2011.

LLUCH, Gemma. Els paratextos i la comprensió lectora en la literatura infantil i juvenil. Articles: revista de didáctica de la llengua i de la literatura, n. 7, 63-72, 1996.

MENDOZA, Antonio. La Educación Literaria desde la Literatura Infantil y Juvenil. In: UTANDA, M. C.; CERRILLO, Pedro; GARCÍA-PADRINO, Jaime (Coord.). Literatura Infantil y educación literaria. Cuenca: Servicio de Publicaciones de la Universidad de Castilla-La Mancha, 2005. p. 33-61.

NÚNEZZ RUIZ, Gabriel. La educación literaria: modelos historiográficos, las humanidades en el bachillerato, literatura infantil y propuestas didácticas. Madrid: Síntesis, 2001.

POZUELO, Jose Maria. Canon: ¿estética o pedagogía? Insula: revista de letras y ciencias humanas, n. 600, p. 3-4, 1996.

POZUELO, Jose Maria; ARADRA, Rosa Maria. Teoría del canon y literatura española. Madrid: Cátedra, 2000.

REDONDO, Jose Carlos; GÓMEZ LÓPEZ, Jesus Isaias. Un canon para la literatura infantil: Harold Bloom y la literatura infantil en inglés. In: CANO VELA, A.; PÉREZ VALVERDE, C. (Coord.). Canon, Literatura infantily juvenil y otras literaturas. Cuenca: Servicio de Publicaciones de la Universidad de Castilla - La Mancha, 2003. p. 531-534. 
TEJERINA, Isabel. Los cien libros del siglo XX: el canon literario y la literatura infantil y juvenil. Lazarillo: revista de la asociación de amigos de libro infantil y juvenil, Madrid, n. 12, p. 17-25, 2004. 
Literatura infantil e educação Children's literature and primária: análise do valor elementary education: an formativo dos livros mais analysis of the educational lidos em Espanha

\title{
Resumo
}

O propósito deste artigo é mostrar a relação que se estabelece entre os livros de literatura infantil mais lidos na Espanha, especificamente no nível da Educação Primária. Pretendemos averiguar se o valor formativo dos mesmos é adequado ou se os textos respondem apenas a um critério comercial. Procuramos debater questôes relevantes como a possibilidade do estabelecimento de um cânone formativo e as dificuldades que lhe são inerentes, o desenvolvimento da leitura e da literatura infantil no currículo oficial, ou mesmo a análise pormenorizada dos textos que são os mais procurados, comprados e lidos pela população infantil na Espanha.

Palavras-chaves: Literatura Infantil. Formação de professores. Promoção da leitura value of the most widely read children's books in spain

\begin{abstract}
The purpose of this article is to present the relationship among the most widely read children's books in Spain, specifically at the elementary school level. We intend to determine if these books have an appropriate educational value or if the texts merely present commercial criteria. We discuss important issues such as the possibility of establishing a formative canon and the difficulties inherent to this process. The development of reading and of children's literature in the official school curriculum and a detailed analysis of those texts that are the most purchased and read by Spanish children is also examined.
\end{abstract}

Keywords: Children's Literature. Teacher education. Promoting reading. 


\section{Eduardo Encabo-Fernández}

E-mail: edencabo@um.es

Isabel Jerez-Martínez

E-mail: isabel.jerezmartinez@uclm.es

Recebido em: 5/3/2012

Versão final recebida em: 19/12/2012

Aprovado em: 20/12/2012 